Information Management and Business Review

Vol. 2, No. 1, pp. 26-37, Jan 2011

\title{
An econometric approach between human development and poverty in North Eastern Region of India
}

\author{
Rudra P. Pradhan \\ Vinod Gupta School of Management, Indian Institute of Technology Kharagpur, India \\ rudrap@vgsom.iitkgp.ernet.in
}

\begin{abstract}
An understanding the linkage between human development and poverty in general and economic development in particular is very imperative in emerging economies in the globe. The objective of this paper is to study the regional variation and causality between human development and poverty in the north-east India. The major finding of this paper is that there exists significant regional variation between human development and poverty in the north eastern states of India. While human development is substantially high in Mizoram and Manipur, it is low in other states. On the contrary, poverty is very low in Mizoram and Manipur, while it is considerably high in other states. The estimated results confirmed that human development (and its individual indicators) has a significant role to alleviate poverty in the north east India.
\end{abstract}

Keywords: Poverty, Human Development, North-East India

\section{Introduction}

Traditionally poverty is treated as a one-dimensional concept. For the sake of simplicity, it has been defined in terms of income only and highly linked with economic growth. That means the effect of higher economic growth would trickle down the poor. But these do not tell us about how an economy has been able over time to build capacities and provide an enabling environment to its citizens for self-actualization. Hence economic growth is necessary but not a sufficient condition for human progress. In fact poverty in the modern day is a multidimensional concept and highly linked with human development. Therefore government needs to actively focus on human development goals and direct and use their resources efficiently so that economic growth leads to empowerment of people and poverty alleviation. In this process, people's needs and their aspirations must be at the centre of all development efforts. The recognition that human existence has dimensions over and beyond the economic conditions of living had been introduced into mainstream economic thought by Professor Amartya Sen, but the credit for operationalizing this concept in the domain of development policy and planning must go to the late Dr. Mehboob-ul-Haq (Pant, 2003).

In the recent era, poverty and human development are the two most socio-economic phenomenons drawing global attention among the academicians, researchers, policymakers, as well as human activists. This is because they are now viewed as the concepts that are more multidimensional, more comprehensive, and relative in nature. They can mean differently to different groups of people in different countries at different points of time. They have varying dimensions and some of these dimensions are still in the process of evolving. For a meaningful discussion and purposeful policy implication, both need to be contextualized in terms of space and time (Bhatt, 2004). This is since there is some degree of integration within and between the two. Keeping in above backdrop, present paper seeks to highlight the status of poverty and human development in NER and their interrelationship. The rest of the paper is divided into six different sections including the earlier introduction. Section II focuses the profile of NER. Section III discusses the extent of poverty in NER. Section IV discourses the trends of human development. Section V examines the interface between human development and poverty. Section VI finally concludes with policy implications thereof.

\section{The Profile of NER}

India has fifteen agro-climatic zones and North Eastern Region (NER) is fall under the Eastern Himalayan Zone (Agarwal, 1996). The region comprises of eight sister states namely Assam, Arunachal Pradesh, Manipur, Mizoram, Tripura, Nagaland, Meghalaya and Sikkim (Umdor and Panda, 2007; Singh et al., 2005; Shimray, 2004; Nayak, 2005). It is geographically isolated region, densely administered, sparsely populated, and least developed region as compared to other states of India. North East occupies an area of $255180 \mathrm{sq} \mathrm{km}$ and comprising of about $8.06 \%$ of India's total land area. Its total population is about 38.5 millions and 
constitutes about $3.7 \%$ of country's total population (See Table 1). About $88 \%$ of its population lives in rural areas and they are very predominating in agriculture (Swaminathan, 1996). The NER is very unique in India because of its strengths and weakness.

Table 1: Geographic and Demographic Aspects of North Eastern States

\begin{tabular}{lclllllllll}
\hline Items & NER & NER1 & NER2 & NER3 & NER4 & NER5 & NER6 & NER7 & NER8 & India \\
\hline Area (in Sq. Km.) & 262276 & 78523 & 10492 & 22327 & 22429 & 16579 & 21087 & 83743 & 7096 & 3166290 \\
Percent all-India & 8.06 & 2.48 & 0.33 & 0.70 & 0.71 & 0.52 & 0.67 & 2.64 & 0.224 & --------- \\
Forest coverage (in \%) & 65.0 & 27.41 & 57.7 & 78.64 & 42.23 & 21.60 & 75.11 & 63.0 & 45.0 & ------- \\
Population (in million) & 39.01 & 26.6 & 3.19 & 2.39 & 2.31 & 1.99 & 0.9 & 1.09 & 0.54 & 102.7 \\
Percent all-India & 3.79 & 2.59 & 0.31 & 0.23 & 0.22 & 0.19 & 0.09 & 0.11 & 0.53 & --------- \\
Sex Ratio & 937 & 932 & 950 & 978 & 975 & 909 & 938 & 901 & 875 & 933 \\
Urbanization (in \%) & 27.8 & 11.1 & 15.3 & 27.5 & 18.6 & 17.2 & 46.1 & 12.8 & 11.1 & 27.8 \\
Population growth $^{1}$ & 23.75 & 18.85 & 15.74 & 30.02 & 29.84 & 64.41 & 29.18 & 26.21 & 33.0 & 21.34 \\
Density of population $^{2}$ & 149 & 65 & 304 & 107 & 103 & 120 & 42 & 13 & 76 & 324 \\
\hline
\end{tabular}

Note: NER: North Eastern Region; NER1: Assam; NER2: Tripura; NER3: Manipur; NER4: Meghalaya; NER5: Nagaland; NER6: Mizoram; NER7: Arunachal Pradesh; NER8: Sikkim; 1: Percentage of population growth in between 1991-2001; 2: Density of population is measured per Sq. KM.

Source: Economic Survey, Government of India; Census of India; and Centre for Monitoring Indian Economy, Mumbai.

Among the strengths, NER is very popular for its biodiversity. About $65 \%$ of the land area in the NER is under forest, making it one of the greenest areas in our country, besides the Andaman and Nicobar Islands (Dutta, 2002; Mitra, 1998). The region is fully bounded by hills (about 65\%) and with mighty Brahmaputra River slashing a central path between its north and south. The flora and fauna of this region is substantially numerous and varied in nature. There exists wide variation in altitude, which is usually ranging from 300 to 5000 meters. Simultaneously, the climate as well as temperature diverges from tropical plains to temperate hills. The region is also well known for its high rainfall along with full of sunshine. The agro-climate of NER has unique diversities and has full potentiality for the development of tourism industry and other industries as well. This is because of its availability of natural resources, mineral resources, cultural and ethnic beauty, hills, heritage sites, beaches, and deep greenest forest. The region is very famous for its strategic location. It is the international border with Bhutan, China, Myanmar, Tibet and Bangladesh (Prabhakra, 2004; Naik and Singh, 2003; Agarwal, 2003). Hence, it has the potentiality to trade with South Asian Countries and having the scope of regional cooperation among the neighboring countries. Last but not the least, the region is very rich in literacy and has a high human development.

Among the weakness, the region is famous for its high humidity and high temperature. The topography is very vibrant, even within the state also. There is large-scale variation in the level of development, which is with respect to their resource endowments, level of industrialization, level of agricultural modernization and the availability of socio-economic infrastructure facilities (Singh and Singh, 2005; Pradhan, 2005). While the region is rich in resource endowment, it is very poor in various sectors like agriculture, industrialization and the availability of infrastructure (Umdor and Panda, 2007; Mohan, 2003; Mahajan, 1996). The majorities are in agriculture (that is about 68\%) and that's because of lack of non-farm activities and low government support. The area is fully dominated by hill and forest. Hence, the size of land holding is very low. The region is very predominant for the tribal composition. Except Assam (about 13\%), all other states are well above $30 \%$ of tribal population.

The overall tribal population is accounted for 58.5\% in NER. The percentage is substantially higher in Arunachal Pradesh, Meghalaya, Mizoram, and Nagaland (Srivastava, 1998). This also involves sub tribes and having distinct languages, dialects, customs, and institutions (Dev, 2004). The region is traditionally inhabited by a large number of ethnic groups and thus, well known for its multi-ethnic setting. Hence, there is lack of social stratification, which has not found in other parts of the country. The region is greatly affected by militancy and immigration (Sebastian, 1986; Roy, 1970). Increased population through immigration and high growth rate of population in the region has caused serious impact on productive resources and the needs of life. Besides, the region is very popular for its high incidence of poverty. This has been separately discussed in the next section. 


\section{The Extent of Poverty in NER}

Poverty defines as a condition of life, which is characterized by deprivation of some sort or the other, and perceived as undesirable by the person ( $\mathrm{s}$ ) concerned or others. It is a multidimensional concept and can be measured in terms of income as well as non-income. By income approach, it interprets in the form of lowness of income, which prevents a family from obtaining and enjoying the basic necessities of life including a minimum of food, clothing, and shelter. Non-income approach of poverty, on the contrary, represents social deprivations such as health, education, sanitation, insurance against mishaps, economic vulnerability, information and participation, political powerlessness and social disadvantage (Bhatt, 2004; Subramanian, 2001, Sen, 2001).

The income approach of poverty at any given point of time depends on the criteria or norms used to define poverty and determine the poverty line. If $\mathrm{Z}$ denotes the poverty line (PL), which is derived on some basis, and the income profiles are $\mathrm{y}_{1} \leq \mathrm{y}_{2} \ldots \leq \mathrm{y}_{\mathrm{q}}<\mathrm{Z} \leq \mathrm{y}_{\mathrm{q}+1} \leq \ldots \leq \mathrm{y}_{\mathrm{n}}$, then the individuals with income less than $\mathrm{Z}$ are identified as poor. The identification issue involves various criteria of defining the poor and arriving at a level of income, which defines the PL. There are two criteria or norms usually employed to define the poverty line: nutritional norm and minimum levels of living. In India, the nutrition approach is very popular. This approach represents that consumer at the PL has to meet a pre-specified nutritional norm (Panda and Rath, 2004). According to Planning Commission, poverty line is measured on the basis of nutritional norm of 2400 calories per person per day in the rural areas and 2100 calories per person per day in the urban areas. It is defined as the level of average per capita expenditure at which this norm is typically attained (GOI, 1993). It is of Rs. 383.18 per capita monthly income in rural areas and Rs. 442.10 per capita monthly income in urban areas (Sidhu et al., 2006).

Coming to the status of poverty, the position of India is very poor in contrast to other neighboring countries (HDR, 2006; Mathur, 2003). Though the proportion of people below the poverty line has come down continuously since the mid-1970s, the latest count (2004-05) based on the uniform recall period (URP) consumption procedure, the total number of poor people is reckoned to be 301.72 million (Chelliah and Shanmugam, 2007). There are differences in the incidence of poverty and composition of the poor among the Indian states. For instance, while there is a significant reduction in poverty in the country, the decline in the incidence of poverty in rural Andhra Pradesh was very steep and much lower than the national average.

The level of urban poverty is very similar to national average but the decline of rural poverty is much lower compared to the national average (Reddy et al., 2003). At the country level, the rate of poverty is very low in Punjab and very high in Orissa and Bihar (GOI, 2006). As far as NER is concerned, the situation is no more different in NER. During 1983, the extent of poverty varies from a low of 1.35 million in Sikkim to a high of 77.69 million in Assam. In the percentage-wise, all the states are in equal position, both in rural and urban area. In 1993-94, the incidence of poverty is again low in Sikkim (i.e.1.84 million) in contrast to a high of 96.36 million in Assam. In the percentage-wise, the rate of poverty varies from a low of $25.66 \%$ in Mizoram to a high of $41.43 \%$ in Sikkim and $40.86 \%$ in Assam. So the best state in NER is Mizoram and worst states are Sikkim and Assam. In 1999, Mizoram still figures the best state, while Tripura witnessed the worst state for its high incidence of poverty (36.55\%). 
Table 2: The Extent of Income Poverty in NER

\begin{tabular}{|c|c|c|c|c|c|c|c|c|c|}
\hline \multicolumn{4}{|c|}{1983} & \multicolumn{3}{|c|}{1993} & \multicolumn{3}{|c|}{1999} \\
\hline $\begin{array}{l}\text { States/ } \\
\text { Regions }\end{array}$ & Rural & Urban & Combined & Rural & Urban & Combined & Rural & Urban & Combined \\
\hline \multirow[t]{2}{*}{ India } & 2520 & 709 & 3229 & 2440 & 763.4 & 3204 & 1932 & 671 & 2603 \\
\hline & $(45.7)$ & $(40.8)$ & $(44.5)$ & $(37.3)$ & $(32.4)$ & $(36.0)$ & $(27.1)$ & $(23.6)$ & $(26.1)$ \\
\hline \multirow[t]{2}{*}{ AP } & 2.7 & 0.12 & 2.82 & 3.62 & 0.11 & 3.73 & 3.8 & 0.18 & 3.98 \\
\hline & $(42.6)$ & $(21.7)$ & $(40.88)$ & $(45.0)$ & (7.73) & (39.35) & $(40.0)$ & (7.47) & (33.47) \\
\hline \multirow[t]{2}{*}{ Assam } & 73.4 & 4.26 & 77.69 & 94.3 & 2.03 & 96.36 & 92.17 & 2.38 & 94.55 \\
\hline & $(42.6)$ & $(21.7)$ & $(40.88)$ & $(45.0)$ & (7.73) & $(40.86)$ & $(40.0)$ & (7.47) & $(36.09)$ \\
\hline \multirow[t]{2}{*}{ Manipur } & 4.76 & 0.89 & 5.65 & 6.33 & 0.47 & 6.80 & 6.53 & 0.66 & 7.19 \\
\hline & $(42.6)$ & $(21.7)$ & $(40.88)$ & $(45.0)$ & $(7.73)$ & (33.78) & $(40.0)$ & $(7.47)$ & $(28.54)$ \\
\hline \multicolumn{2}{|c|}{ Meghalaya 5.05} & 0.57 & 5.62 & 7.09 & 0.29 & 7.38 & 7.89 & 0.34 & 8.23 \\
\hline & $(42.6)$ & $(21.7)$ & $(40.88)$ & $(45.0)$ & (7.73) & (37.92) & $(40.0)$ & $(7.47)$ & (33.87) \\
\hline \multirow[t]{2}{*}{ Mizoran } & n 1.59 & 0.37 & 1.96 & 1.64 & 0.32 & 1.94 & 1.4 & 0.45 & 1.85 \\
\hline & $(42.6)$ & $(21.7)$ & (40.88) & $(45.0)$ & $(7.73)$ & $(25.66)$ & $(40.0)$ & $(7.47)$ & (19.47) \\
\hline \multicolumn{2}{|c|}{ Nagaland 3.19} & 0.31 & 3.5 & 4.85 & 0.20 & 5.05 & 5.21 & 0.28 & 5.49 \\
\hline & $(42.6)$ & $(21.7)$ & $(40.88)$ & $(45.0)$ & $(7.73)$ & (37.92) & $(40.0)$ & (7.47) & (32.67) \\
\hline \multirow[t]{2}{*}{ Tripura } & 8.35 & 0.60 & 8.95 & 11.41 & 0.38 & 11.79 & 12.53 & 0.49 & 13.02 \\
\hline & $(42.6)$ & $(21.7)$ & $(40.88)$ & $(45.0)$ & (7.73) & (39.01) & $(40.0)$ & (7.47) & (36.55) \\
\hline \multirow[t]{2}{*}{ Sikkim } & 1.24 & 0.11 & 1.35 & 1.81 & 0.03 & 1.84 & 2.0 & 0.04 & 2.04 \\
\hline & $(42.6)$ & $(21.7)$ & $(40.88)$ & $(45.0)$ & (7.73) & (41.43) & $(40.0)$ & $(7.47)$ & $(34.44)$ \\
\hline \multirow[t]{2}{*}{ NER } & 100.31 & 7.23 & 107.54 & 131.06 & 3.83 & 134.89 & 131.53 & 4.82 & 136.35 \\
\hline & $(42.6)$ & $(21.7)$ & $(40.88)$ & $(45.0)$ & (7.73) & (39.35) & $(40.0)$ & (7.47) & (33.47) \\
\hline \multicolumn{2}{|c|}{ Best State 16.79} & 11.85 & 28.64 & 17.76 & 7.35 & 25.11 & 10.2 & 4.29 & 14.49 \\
\hline \multicolumn{2}{|c|}{ (Punjab) (13.2) } & $(23.79)$ & (16.18) & (11.95) & (11.35) & $(11.77)$ & $(6.35)$ & $(5.75)$ & $(6.16)$ \\
\hline \multirow{3}{*}{ Worst St } & tate 164. & 5516.66 & 181.31 & 450.86 & 42.49 & 493.35 & 143.69 & 25.4 & 169.09 \\
\hline & $(67.53)$ & $(49.15)$ & $(65.29)$ & (58.21) & $(34.5)$ & $(54.96)$ & $(48.01)$ & $(42.83)$ & $(47.15)$ \\
\hline & & \multicolumn{2}{|c|}{ (Orissa) } & & \multicolumn{2}{|l|}{ (Bihar) } & & \multicolumn{2}{|c|}{ (Orissa) } \\
\hline
\end{tabular}

Source: National Human Development Report (NHDR), 2001

To summarize, the level of poverty is very low in Mizoram and Manipur and other states have high incidence of poverty and they are also above than that of country's average. Though the incidence of poverty in NER has exhibited a downward trend over the years, it is substantially low in contrast to other states of the country. There is also large scale variation in rural-urban area (Ninagombam, 2007). While the level of poverty is high in rural area, it is low in urban area (See Table 2).

The social approach of poverty is more complex and extremely multidimensional in nature. Social poverty reflects lack of education, health, empowerment, participation, etc. But in the present context, we are 
describing the situation with respect to education and health only. While illiteracy rate has been taken as a parameter under education, infant mortality rate has been taken as a parameter under health. Coming to the status, India's position is very poor in contrast to other developed and developing countries (HDR, 2006). Again there is large-scale variation among the states of India. While social poverty is very low in Kerala, it is high in Bihar, Madhya Pradesh, and Orissa. The variation also exists within the states (GOI, 2006). The situation is no more different in NER. The level of illiteracy is high in Arunachal Pradesh, Meghalaya and Assam and Tripura and considerably low in Mizoram, Nagaland, and Tripura. Mizoram is all time best state in NER, while Arunachal Pradesh is all time worst state. But, over the years, all states accommodate themselves to reduce the level of illiteracy. On the contrary, the level of infant mortality rate is much higher in Assam, Arunachal Pradesh, and Sikkim and lower in Mizoram, Manipur, and Nagaland (See Table 3). It is observed that the extent of income poverty is very close with social poverty. Where social poverty is high, there is highincome poverty and vice versa.

Table 3: The Extent of Non- Income Poverty in NER

\begin{tabular}{|c|c|c|c|c|c|c|}
\hline \multirow{2}{*}{$\begin{array}{l}\text { States/ } \\
\text { Regions }\end{array}$} & \multicolumn{3}{|c|}{ Education (Illiteracy Rate) } & \multirow{2}{*}{$\begin{array}{l}\text { Health } \\
2001\end{array}$} & \multicolumn{2}{|c|}{ (Infant Mortality Rate) } \\
\hline & 2001 & 1991 & 1981 & & 1991 & 1981 \\
\hline India & 34.6 & 47.8 & 56.4 & 71 & 77 & 115 \\
\hline AP & 45.3 & 58.4 & 74.5 & 44 & 91 & 126 \\
\hline Assam & 35.7 & 47.1 & NA & 78 & 92 & NA \\
\hline Manipur & 31.1 & 40.1 & 50.4 & 25 & 28 & 32 \\
\hline Meghalaya & 36.7 & 50.9 & 58.0 & 52 & 80 & 79 \\
\hline Mizoram & 11.5 & 17.7 & 25.7 & 23 & 53 & 83 \\
\hline Nagaland & 32.9 & 38.4 & 49.8 & 15 & 51 & 68 \\
\hline Tripura & 26.3 & 39.6 & 49.9 & 49 & 82 & 130 \\
\hline Sikkim & 30.3 & 43.1 & 58.4 & 52 & 60 & 127 \\
\hline NER & 31.2 & 41.9 & 52.4 & 42 & 67 & 92 \\
\hline \multirow[t]{2}{*}{ Best State } & 09.1 & 10.2 & 18.4 & 16 & 28 & 32 \\
\hline & \multicolumn{3}{|c|}{ (Kerala) } & (Kerala) & \multicolumn{2}{|c|}{ (Manipur) } \\
\hline Worst State & 52.5 & 61.5 & 25.5 & 97 & 133 & 163 \\
\hline \multicolumn{4}{|c|}{ (Bihar) } & (Madhya Prades & & (Orissa) \\
\hline
\end{tabular}

Source: National Human Development Report (NHDR), 2001

\section{The Extent of Human Development in NER}

Human development is a mirror of a nation/ region. It is an outcome/ integration of socio-economic development. Since the basic objective of development of a nation/ region is to improve the welfare of the people, every nation/ region strives hard not only to increase her wealth and productive resources but also to ensure better standard of living of her citizens by providing them with adequate food, cloth, education, etc. However, technical considerations of the means to achieve human development and use of statistical aggregates to measure national income and its growth have at times obscured the fact that the primary objective of development is to benefit people. National income figures, though useful for money purposes, neither reveal its composition nor its real beneficiaries. Of course, people want higher incomes as one of their options; it is neither the sum total of human life nor an end in itself. Hence, the expansion of output and wealth is only a means; end of development is the welfare of human beings. Technically, it is captured through a composite index and popularly known as Human Development Index (See HDR, 1990; 2002; Haq, 
2003; 1995). The index represents as a process of enlarging people's choices, particularly with respect to long and healthy life, to acquire knowledge and to have access to resources needed for a decent standard of living. The scope of human development, however, does not end there. Some other valuable choices range from economic, political, and social freedom to the opportunities guaranteeing self-esteem, human rights, creative and productive lives, and creation and diffusion of technology (HDR, 2001).

The construction of HDI follows two-step procedures. The first step is normalization, which involves the linear transformation of crude data, comprising the two elementary operations of translation (addition or subtraction of a constant from all observations of a given variable, thus shifting the origin) and/ or expansion (multiplication or division of all values by a constant, thus changing the scale). Following Ott (1978) the normalized variables will be referred to as indicators. The indicator corresponding to the crude data $X_{i}$ will be denoted by $\mathrm{I}_{\mathrm{i}}\left(\mathrm{X}_{\mathrm{i}}\right)$. In practice, a variety of normalization procedures are being applied. Two broad categories are: ranging and standardization. But here we apply the ranging technique only and the objective is to transform the crude data into 0-1 scales. In these approaches the largest observation has the value 1 , but the smallest observations may or may not have the value 0 :

$$
\begin{gathered}
I_{i}\left(X_{i}\right)=\frac{X_{i}}{X_{i}^{\max }} \text { or } \\
I_{i}\left(X_{i}\right)=\frac{\left(X_{i}-X_{i}^{\min }\right)}{\left(X_{i}^{\max }-X_{i}^{\min }\right)}
\end{gathered}
$$

Where, $\mathrm{X}_{\mathrm{i}}{ }^{\min }=$ Minimum of variable $\mathrm{i} ; \mathrm{X}_{\mathrm{i}} \max =$ Maximum of variable $\mathrm{i}$.

The first equation retains the origin, i.e., zero is mapped to zero and in the second equation, the smallest observation is mapped to zero.

The second step of this process is aggregation. For that, we have used the following formula (See Van den Bergh and Veen-Groot, 2001):

$$
H D I=\frac{1}{N} \sum_{i} I_{i}\left(X_{i}\right)
$$

Where, HDI is represented as Human Development Index. It is to be noted that the value of HDI is nonnegative and lies between zero and one. Any value closer to one indicates high human development and any value closer to zero indicates low human development. The components used for this HDI are income, education, and health. For income, we take per capita net state domestic product; for education, we take literacy rate; and for health, we take Infant Survival Rate (ISR). While the lack of same leads to poverty (named as Human Poverty Index), the prosperity of it leads to human welfare (represented as Human Development Index). Coming to the status of human development, the position of India is very poor in contrast to other developing countries in the world (HDR, 2006). In the country specific, India has twin problems: low rank and regional disparities across and within the states. As far as NER is concerned, the situation is no more different (Nayak, 2005). During 1981, HDI varies from a low of 0.449 in Arunachal Pradesh to a high of 0.638 in Mizoram. In 1991, Meghalaya is the lowest HDI and Mizoram is still occupied the first position. Similarly in 2001, Assam is having lowest HDI, while Mizoram still witnessed the highest HDI (See Figure 1). 
Figure 1: The Extent of Human Development in NER

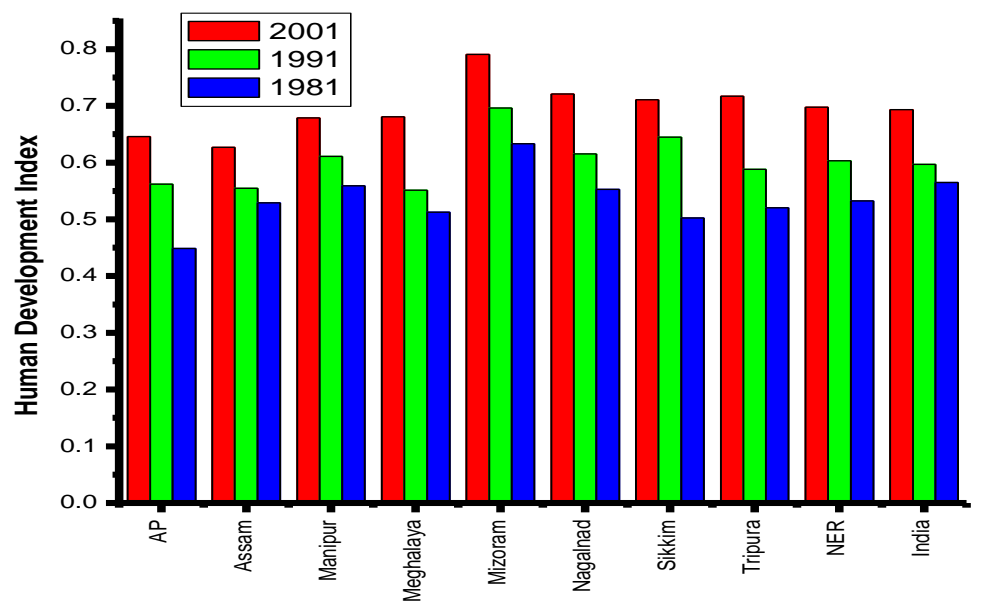

1. Coefficient of variation among eight sister states have been declined over the years (i.e. $1981=9.97 \%$; $1991=8.30 \%$; and $2001=$ 7.30\%).

2. Mizoram is all time favorite state in NER.

Source: Calculated by Author

In short, there are three basic features we have been observed in NER with respect to HDI. First, Mizoram is all time favourite state in the region; second, over the years, there is substantial improvement of HDI in all the states of NER; third, there is regional disparity among the states of NER but it has been declining over the years. This is because the coefficient of variation has been declined from $9.97 \%$ in 1981 to $8.3 \%$ in 1991 and $7.3 \%$ in 2001 . However, there is yawing gap between urban and rural areas. While human development is low in rural area, it is high in urban area.

Table 4: The Extent of Human Development in NER

\begin{tabular}{llllllllll}
\hline & \multicolumn{3}{c}{$\mathbf{1 9 8 1}$} & \multicolumn{3}{c}{ 1991 } & \multicolumn{3}{c}{$\mathbf{2 0 0 0}$} \\
\hline States/Regions & \multicolumn{1}{l}{ Rural Urban } & Disparity & \multicolumn{2}{c}{ Rural Urban } & Disparity & \multicolumn{2}{c}{ Rural Urban } & Disparity \\
\hline India & 0.263 & 0.442 & 0.179 & 0.340 & 0.511 & 0.171 & 0.380 & 0.584 & 0.204 \\
AP & 0.228 & 0.419 & 0.191 & 0.300 & 0.572 & 0.272 & 0.379 & 0.622 & 0.243 \\
Assam & 0.261 & 0.380 & 0.119 & 0.326 & 0.555 & 0.229 & 0.330 & 0.613 & 0.283 \\
Manipur0.440 & 0.553 & 0.113 & & 0.503 & 0.618 & 0.115 & 0.404 & 0.640 & 0.236 \\
Meghalaya & 0.293 & 0.442 & 0.149 & 0.332 & 0.624 & 0.292 & 0.390 & 0.671 & 0.281 \\
Mizoram & 0.381 & 0.558 & 0.177 & 0.464 & 0.648 & 0.184 & 0.473 & 0.687 & 0.214 \\
Nagaland & 0.295 & 0.519 & 0.224 & 0.442 & 0.633 & 0.191 & 0.477 & 0.738 & 0.261 \\
Tripura 0.264 & 0.498 & 0.234 & & 0.368 & 0.551 & 0.183 & 0.397 & 0.656 & 0.259 \\
Sikkim & 0.302 & 0.515 & 0.213 & 0.398 & 0.618 & 0.220 & 0.396 & 0.571 & 0.175 \\
\hline
\end{tabular}

Source: National Human Development Report (NHDR), 2001

The rural-urban disparity index varied from a lowest figure of 0.113 in Manipur to the highest of 0.234 in Tripura. The situation is more or less same in 1991. But in 2000, the highest disparity was observed in Assam (0.283) and the lowest has observed in Sikkim (0.175). The position of Meghalaya in this regard is worth mentioning. Her rank in rural-urban disparity has been substantially deteriorated over time and also in ranks (See Table 4). Over and above, we have been observed that there is close association between human development and poverty. Where the level of human development is high, there is low incidence of poverty 
and vice versa. Hence we can interpret that poverty has come to be increasingly seen as deprivation of capability rather than merely a lowness of income. However income is clearly one of the major causes of poverty, since the lack of income can be principal reason for a person's capability deprivation (Sen, 1999).

\section{The Interface between Human Development and Poverty in NER}

This section scans the interface between human development and poverty. There are two approaches through which we can examine the nexus between human development and poverty. First, the production based regression approach, where one way causality is allowed and second, the time series approach, where the reverse causality is allowed. Since our empirical investigation is based on cross sectional analysis, we are bound to use traditional regression approach. It has already been predicted that a high level of human development leads to low existence of poverty (and vice versa). In order to justify the same, we have used the following econometric model:

$$
P O V_{i, t}=\alpha_{0}+\beta_{0} H D I_{i, t}+\zeta_{i t}
$$

Where, POV = Rate of poverty; HDI = Human Development Index; $\mathrm{i}=$ Corresponding states; $\mathrm{t}=$ Time periods; $\xi$ is the error terms, which capture the missing variables; $\alpha$ and $\beta$ are parameters, which to be estimated. Here, we have two hypotheses $\left(\mathrm{H}_{1}\right.$ and $\left.\mathrm{H}_{2}\right)$ to verify

$\mathrm{H}_{1}$ : A high level of human development leads to low level of poverty. In other words, they are negatively related to each other.

$\mathrm{H}_{2}$ : Each dimension of HDI would have negative association with poverty. That means a high level of education (or income or health) leads to low level of poverty.

The empirical analysis is based on three cross sectional years (viz. 1981, 1991 and 2001), where state represents the unit of analysis. We applied pooled data analysis to investigate the validity of hypotheses. We have also incorporated the intercept and slope dummies to examine whether the relationship between poverty and human development is stable or changing over time. For this, the earlier model has been modified:

$$
P O V_{i, t}=\alpha_{0}+\beta_{0} H D I_{i, t}+\alpha_{1} D_{1}+\alpha_{2} D_{2}+\beta_{1} D_{1} H D I_{i, t}+\beta_{2} D_{2} H D I_{i, t}+\zeta_{i t}
$$

Where, $D_{1}$ and $D_{2}=$ Dummy variables; $\xi$ is the error terms, which capture the missing variables; $\alpha$ 's, $\beta$ 's, are parameters, which to be estimated. The corresponding hypothesis $\left(\mathrm{H}_{3}\right)$ is that there is structural break in the process of human development to poverty during 1981 to 2001. The descriptive statistics and the estimated results are reported in Table 5 and Figures 2 and 3. Table 5 presents the means and standard deviations, and the correlation coefficients. All correlations coefficients are at the average level, which does not indicate any serious multicolinearity problems. The correlation coefficient indicates that all variables of human development and Human Development Index (HDI) are positively associated with each other and they are all negatively associated with level of poverty. This appears to support our expectation.

Table 5: The Extent of Non- Income Poverty in NER

\begin{tabular}{llllllllll}
\hline & MIN & MAX & MEA & SD & EDU & HEA & PCS & HDI & POV \\
EDU & 0.28 & 0.97 & 0.635 & 0.148 & 1.00 & --- & --- & --- & --- \\
HEA & 0.88 & 0.99 & 0.945 & 0.305 & 0.685 & 1.00 & $-\cdots$ & $-\cdots$ & $-\cdots$ \\
PCS & 0.13 & 0.45 & 0.254 & 0.104 & 0.491 & 0.488 & 1.00 & $-\cdots$ & $-\cdots$ \\
HDI & 0.45 & 0.79 & 0.611 & 0.080 & 0.913 & 0.758 & 0.795 & 1.00 & $-\cdots$ \\
POV & 19.47 & 44.5 & 36.44 & 5.699 & -0.749 & -0.645 & -0.581 & -0.792 & 1.000 \\
\hline
\end{tabular}

Note: MIN: Minimum; MAX: Maximum; MEA: Mean; SD: Standard Deviation; EDU: Education (Literacy Rate); HEA: Health (Infant Survival Rate); PCS: Per capita State Domestic Product; HDI: Human Development Index; and POV: Rate of Poverty.

Source: Calculated by Author 
Figure 2 presents the bivariate regression results, where poverty has been taken as dependent variable and HDI and its components are taken as independent variables. The estimated results reflect that HDI $(t=-6.97$; $P<0.00$ ) has significant negative impact on poverty in the northeastern region of India. This is supported by both $\mathrm{R}^{2}(0.635)$ and adjusted $\mathrm{R}^{2}(0.622)$, which are also statistically significant at $1 \%$. This suggests that HDI has predictive effects on poverty alleviation. In particular, we can justify that a high level of HDI is more likely to have low level of poverty and vice versa. The above results support the first hypothesis of this study. Coming to second hypothesis (i.e. through its dimension), the results find that education $(-5.95 ; \mathrm{P}<0.00)$, health $(-4.22 ; \mathrm{P}<0.00)$ and income $(-3.28 ; \mathrm{P}<0.00)$ are highly significant on poverty alleviation. These are all supported by $\mathrm{R}^{2}$ and adjusted $\mathrm{R}^{2}$, which are also statistically significant at $1 \%$ level. It is, however, observed that the impact is high on education $\left(R^{2}=0.56\right)$, which is followed by health $\left(R^{2}=0.39\right)$ and income $\left(\mathrm{R}^{2}=0.34\right)$. This suggests that a high level of education, health, and income would bring the poverty at low level. This is also verified the second hypothesis of this study.

Figure 2: The Interface between Human Development and Poverty in NER

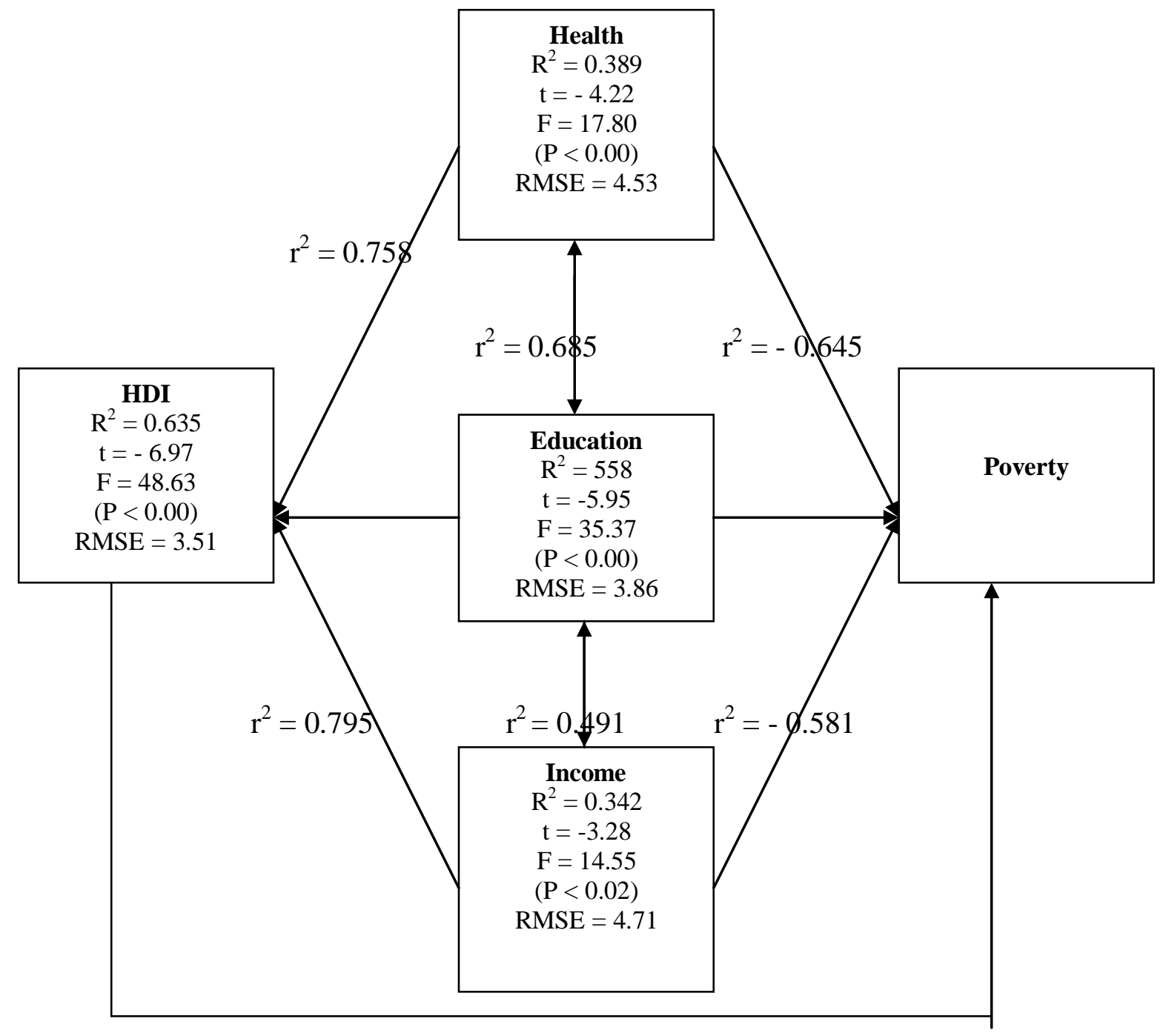

Source: Calculated by Author 
Figure 3: Findings for Causality between Human Development and Poverty

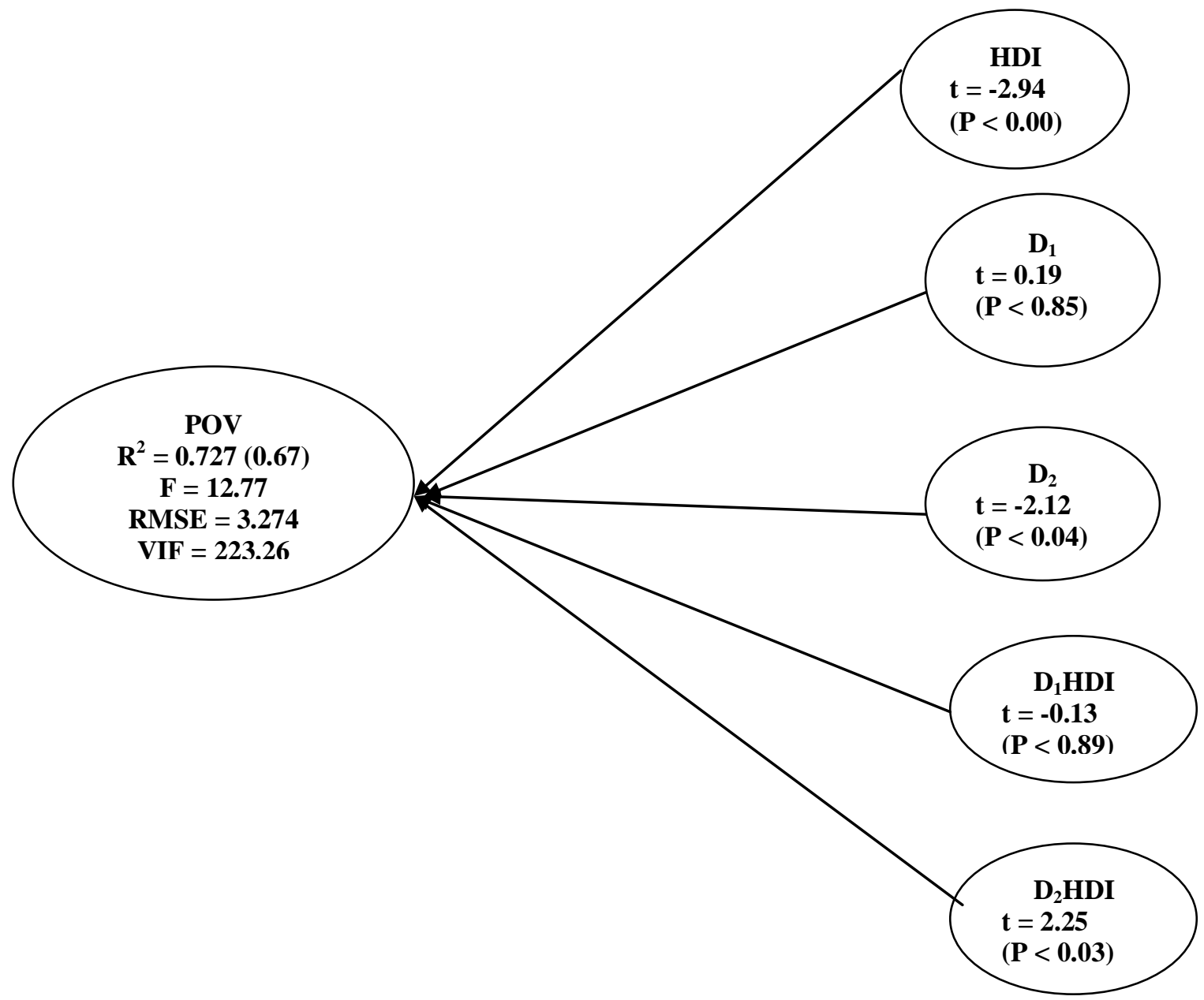

Note: POV: Rate of Poverty; HDI: Human Development Index (Representing Human Development); $\mathrm{D}_{1}$ and $\mathrm{D}_{2}$ : Dummy variables; $\mathrm{R}^{2}$ : Coefficient of Determination; F: F-Statistics; RMSE: Root Mean Square Error; VIF: Variance Inflator Factor.

Source: Calculated by Author

Finally, we also investigate the structural break between HDI and poverty in the NER during 1981 and 2001. We use two dummy variables $\left(D_{1}\right.$ and $\left.D_{2}\right)$ for establishing the same. The estimated results in this section are reported in Figure 2. The results indicate that HDI $(t=-2.94 ; \mathrm{P}<0.00)$ has significant impact on poverty. But between $D_{1}$ and $D_{2}, D_{2}(-2.12 ; p<0.04)$ is statistically significant, while $D_{1}$ does not find any statistical significance $(\mathrm{t}=0.19 ; \mathrm{p}<0.85$.). This represents that there is presence of structural break between 1991 and 2001, while it is not present between 1981 and 1991 (Figure 3). That means the corresponding hypotheses, which we have cited above, are partially true in the north-east India during the period 1981 to 2001 . The above findings are very important for the policymakers to determine the budget allocations for all heads of human development, which will certainly help to achieve high human development and long term poverty alleviation in the north eastern region.

\section{Conclusion and Policy Implications}

The paper evaluates the status of North Eastern Region (NER) of India with respect to poverty and human development during the period 1981 to 2001 .Our analysis presents a mixed picture. While the region is well known for its high human development, it is equally well known for her high poverty. The level of human 
development is significantly high in Mizoram, Manipur and Nagaland and low in Arunachal Pradesh, Assam, Megahalaya, and Tripura. On the contrary, the rate of poverty is low in Mizoram and Manipur, Nagaland and Sikkim and high in Arunachal Pradesh, Assam, Megahalaya, and Tripura. It is observed that the status of HDI have been improved over the years, while the incidence of poverty have been declined substantially in all the states of NER. Hence there is some close connection between the two. This has also been statistically investigated. The estimated results confirmed that there is significant negative association between poverty and HDI (and its individual dimensions). That means an increase of HDI and its dimension will lead to decline of poverty in the region/states. The paper also investigated the structural break in the process of human development to poverty in NER during 1981 to 2001. The estimated results confirmed that there is structural break in 2001, while it is not in 1981. This is very useful for the policymakers to determine the budget allocations for all heads of human development and that will help to achieve long-term poverty alleviation in the region. But we have not discussed the impact of budget allocation on human development indicators and its effect on poverty. This is one of the major limitations of the paper. Besides, we have also not discussed the time series nexus between poverty and human development. Over and above, the policy implication of this paper is that there is need of significant stress on each indicators of human development to reduce the incidence of poverty in the northeast India. A piece-meal approach to such a vital issue is of serious consequences. What is urgently required is to improve the same at any cost. A well-integrated programme with a clear bias towards the disadvantaged states and for that matter, the disadvantaged people may bring the desired solutions. It is not a daunting task, if there is adequate political will in the economy.

\section{References}

Agarwal, A. K. (2003): Globalization and Its Relevance for North-East India: A Policy Perspective, Indian Development Review, 1(1): 77-86.

Agarwal, A. K. (1996): Agricultural System and Behaviour in North Eastern States, in Mahajan, V. S. (Ed.), Agriculture, Rural Development and Panchayati Raj, Deep and Deep Publications, New Delhi.

Bhatt, M. S. (2004): Poverty and Food Security in India: Problems and Policies, Aakar Publication, New Delhi.

Chelliah, R. J. and Shanmugam, K. R. (2007): Strategy for Poverty Reduction and Narrowing Regional Disparities", Economic and Political Weekly, 42 (34):3475-3481.

CMIE (2000): Centre for Monitoring Indian Economy (CMIE), Mumbai.

Dev, R. (2004): Human Rights, Relativism, and Minorities in North-East India, Economic and Political Weekly, 39 (43): 4747-4752.

Dutta, P. C. (2002): Development of Social Forestry in Assam of North Eastern Region, Indian Journal of Regional Science, 34 (2): 52-62.

GOI. (1993): Report of the Expert Group on Estimation of Proportion and Number of Poor. Planning Commission, Government of India (GOI), New Delhi

GOI. (2006): Economic Survey, Ministry of Finance. New Delhi: Government of India.

Haq, M. ul. (2003): The Birth of Human Development Index, in Fukuda-Parr, S., Shiva Kumar, A. K. (Eds.), Readings in Human Development, Oxford University Press, Oxford.

Haq, M. ul. (1995): Reflections of Human Development, Oxford University Press, New York.

HDR (2006): Human Development Report (HDR), United Nations Development Programme (UNDP). New York: Oxford University Press.

HDR (2002): Human Development Report, UNDP, Oxford University Press, New York.

HDR (2001): Human Development Report, UNDP, Oxford University Press, New York.

HDR (2000), Human Development Report, UNDP, Oxford University Press, New York.

HDR (1990): Human Development Report, UNDP, Oxford University Press, New York.

Mahajan, V. S. (1996): Poverty Alleviation in North-East- Basic Groundwork Should be Prepared First, in Mahajan, V. S. (Ed.) Agriculture, Rural Development and Panchayati Raj, Deep and Deep Publications, New Delhi.

Mathur, S. K. (2003): Trade Liberalization and the Poor: A Framework for Poverty Reduction Policies with Special Reference to Some Asian Countries including India, Indian Development Review, 1(2):179-230 
Mitra, A. (1998): Environment and Sustainable Development in the Hilly Regions of North East India: A Study in Arunachal Pradesh, International Journal of Social Economics, 25 (2/4):196-206.

Mohan, R. (2003): Economic Development of the North East Region: Some Reflections, Reserve Bank of India Bulletin, 12:925-937.

Naik, S., Singh, S. (2003): North Eastern States: A Rural Development and Poverty Alleviation Perspective, Yojana, 47(3):30-38.

Nayak, P. (2005): A Human Development Approach to the Status of North East, Available at http://129.3.20.41/eps/get/papers/0509/0509003.pdf.

NHDR. (2001): National Human Development Report (NHDR), Planning Commission, Government of India, New Delhi.

Ningombam, J. (2007): Rural Poverty in North Eastern Region: Problems and Prospects, Journal Global Economy, 3(1): 29-32

Ott, W. (1978): Environmental Indices: Theory and Practice, Ann Arbor, Michigan

Panda, M. K. and Rath, K. P. (2004): Price Changes and Some Underlying Aspects of Measurement of Poverty, Journal of Quantitative Economics, 2(1): 25-43.

Pant, K. C. (2003): India's Development Scenario: Next Decade and Beyond, Academic Foundation, New Delhi.

Prabhakra, M. S. (2004): Is North-east India Landlocked, Economic and Political Weekly, 39(42):4606-4608.

Pradhan, R. P. (2005): Socio-economic Disparity in North Eastern Regions of India: Prospective Challenges and Opportunities, Indian Journal of Social Development, 5(1): 93-113

Reddy, S. S., Galab, S. and Rao, P. P. (2003): Trends and Determinants of Poverty, in Rao, C. H. H., Dev and S. M. (Eds.), Andhra Pradesh Development: Economic Reforms and Challenges Ahead, Manohar Publications, New Delhi.

Roy, B. B. K. (1970): Demographic and Socio-Economic Profile of the Hill Areas of North East India, Registrar General of India, New Delhi.

Sebastean, A. (1986): Migrants in North-Eastern Region of India. In: Datta Ray, B. (ed.), The Pattern and Problems of N-E India, Uppal Publications, New Delhi.

Sen, A. K. (2001): What is Development About, in Meier, G. and J. E. Stiglitz (Eds.), Frontiers of Development Economics: The Future in Perspective, Oxford University Press, Oxford.

Sen, A. K. (1999): Development as Freedom, Oxford University Press, New Delhi.

Shimray, U. A. (2004): Socio-Political Unrest in the Region Called North-east India, Economic and Political Weekly, 39 (42):4637-4643

Sidhu, M. S., Toor, M. S. and Dhadli, T. K. (2006): Urban Poverty in India: Some Issues, Southern Economist, 44(21), 7-11.

Singh, R. P., Kumar, R. and Singh, N. P. (2005): Economic Growth and Sustainability in North East Region (NER) of India: Perspective, Journal of Rural Development, 24 (1): 89-104.

Srivastava, S. C. (1998): Development and Disparity: Agriculture in North East India, Indian Journal of Economics, 79 (313), 195-217.

Subramanian, S. (2001): India's Development Experience. New Delhi: Oxford University Press

Swaminathan, M. S. (1996): Report of the Committee on Remedying Agricultural Progress in Backward Areas, Ministry of Agriculture, Government of India, New Delhi.

Umdor, S., Panda, B. (2007): Economic Infrastructure in North-East India: An Analysis, Man and Development, 29 (1),113-130.

Van den Bergh, J. C. J. M and Veen-Groot, D. B. V. (2001): Constructing Aggregate Environmental- Economic Indicators: A Comparison of 12 OECD Countries, Environmental Economics and Policy Studies, 4:1-16. 